\title{
Nutrition, physical activity and screen time policies and practices in family day care in NSW, Australia
}

\section{Erin M Kerra,g, Bridget Kellya, Jennifer Normanª,b,c, Susan Furberb,c,d, Lara Hernandez ${ }^{e}$, Megan L Hammersley ${ }^{a, c}$, Sarah Ryan ${ }^{a}$, Lisa Francob, Cecilia Vuong ${ }^{\dagger}$ and Anthony D Okely ${ }^{a, c}$}

a Early Start, Faculty of the Arts, Social Sciences and Humanities, University of Wollongong, NSW, Australia

b Health Promotion Service, Illawarra Shoalhaven Local Health District, Wollongong, NSW, Australia

c Illawarra Health Medical Research Institute, Wollongong, NSW, Australia

a School of Health and Society, Faculty of the Arts, Social Sciences and Humanities, University of Wollongong, Australia

e NSW Ministry of Health, Sydney, Australia

${ }^{\dagger}$ Health Promotion Service, South Western Sydney Local Health District, NSW, Australia

g Corresponding author: emk833@uowmail.edu.au

\section{Article history}

\section{Publication date: October 2021}

Citation: Kerr EM, Kelly B, Norman J, Furber S, Hernandez L, Hammersley ML, Ryan S, Franco L, Vuong C, Okely AD. Nutrition, physical activity and screen time policies and practices in family day care in NSW, Australia. Public Health Res Pract. 2021; Online early publication. https://doi. org/10.17061/phrp31342114

\section{Key points}

- We developed a policy review tool to assess the extent to which family day care service providers' policies adhere to national standards and relevant guidelines

- Service provider policies and practices were more likely to promote healthy eating compared with infant feeding, physical activity and screen time

- Service providers trained in the Munch \& Move program were more likely to offer healthy eating and physical activity professional development to educators and have more comprehensive nutrition policies

\section{Introduction}

In Australia, family day care (FDC) is an approved Early Childhood Education and Care (ECEC) service where educators provide education and care for up to seven children aged 0-12 years, but only four children younger than school age (0-5 years), in a home environment. ${ }^{1}$ More than 130000 Australian children aged $0-12$ years attended FDC in 2018²; comprising $12 \%$ of the ECEC sector (excluding outside school hours care services). Australian FDC services operate under a two-tiered structure: the service provider operates at the first tier at the organisational level and educators are registered through the service provider at the second tier providing education and care directly to the children. The service providers act as coordination units, monitoring and supporting educators to ensure they comply with service providers' policies as well as national standards and regulations. ${ }^{3}$

Munch \& Move is a program designed to promote healthy eating, physical activity and reduced screen time in the ECEC sector. ${ }^{4}$ The program began in 2008 and was enhanced in 2016 with health promotion officers providing additional support to service providers ${ }^{5}$, to help disseminate training, resources and information to educators and/or families. Development work for Munch \& Move was conducted with centre-based services, with adaptations appropriate to FDC, however, the impact of the program has only been evaluated in preschools. ${ }^{6}$ The aim of this study was to examine the effect of Munch \& Move training on existing policies, resources and professional development used by FDC service providers that were designed to promote healthy eating and physical activity, and reduce screen time for children aged $0-5$ years. 


\section{Methods}

\section{Study design and setting}

A cross-sectional study was conducted with FDC service providers from South Western Sydney and Illawarra Shoalhaven Local Health Districts in NSW, Australia, from February to September 2018. All FDC service providers in these districts $(n=85)$ were invited to participate in a telephone or face-to-face survey and policy review. The list of service providers was obtained from the Australian Children's Education \& Care Quality Authority (ACECQA). ${ }^{7}$

\section{Data collection measures: policy review and survey}

Service providers' practices and policies were assessed in two ways: policy review and survey. We defined a service provider policy as a formal written policy owned by the service provider. To undertake the policy review, four separate policy review tools were developed to assess policies containing guidelines about nutrition, infant feeding and breastfeeding, physical activity and screen time. The policy review criteria were based on seven National and NSW nutrition and physical activity guidelines detailed on the 'Children's health and safety' resource page of the ACECQA website. ${ }^{8}$ Supplementary tables 1-4 outline the criteria in each policy review tool and the source of each criterion (available from: doi. org/10.6084/m9.figshare.16676296).

Researchers independently reviewed each policy twice and each individual criterion was categorised as either 'no information provided'; 'topic is partially covered;' or 'topic is fully covered'; and given scores of $0,0.5$, or 1.0 , respectively. Policy scores were compared and inconsistent scores were determined by consensus. The total number of criteria covered were summed to give an overall score for each individual policy. Policies were classed as comprehensive if more than two-thirds of the criteria were covered.

A 25-item survey was developed by the authors focusing on policies, resources provided to families and educators, and the type of professional development accessed about infant feeding, nutrition, physical activity and screen time for children aged 0-5 years.

The survey was reviewed by 12 experts experienced in health promotion and research in ECEC settings from the University of Wollongong and NSW Health. The survey was tested with two FDC service providers from another local health district. The lead author and a research assistant conducted the 30-minute survey with first-tier FDC employees on the phone or in person. Service providers' postcodes were used to determine socioeconomic status and remoteness using standardised indices. 9,10 Ethics approval was obtained from the University of Wollongong Human Research Ethics Committee (HREC/17/WGONG/139).

\section{Data analysis}

Statistical analyses were performed using IBM SPSS Statistics for Windows (Armonk, NY: IBM Corp; version 23). Descriptive statistics were calculated for all variables. Fisher's exact test was used to test for associations between service providers trained or not trained in Munch \& Move, their provision of resources and professional development to educators and families, and their possession of policies. Independent t-tests (parametric data) and Mann-Whitney $U$ test (nonparametric data) were used to test for differences between policy scores and service providers trained or not trained in Munch \& Move. Average policy scores were calculated from service providers with a policy in the category. Significance levels were set at $p<0.05$.

\section{Results}

Thirty-four (40\%) service providers from the ACECQA list ceased operating during the study period. Of the remaining 51 service providers, 28 participated (55\%). These 28 service providers had 885 registered educators in total, ranging from 5 to 91 each. All service providers enrolled children aged $0-12$ years. Most service providers (22 of 28) were located in the most disadvantaged areas (SEIFA quintiles 1 and 2) $)^{9}$ and most providers (25 of 28) were in major cities. ${ }^{10}$ Table 1 shows nutrition, physical activity and screen time information, and resources and professional development, offered by service providers that were trained and not trained in Munch \& Move. Service providers trained in Munch \& Move were more likely to offer professional development to educators on healthy eating ( $90 \%$ vs. $25 \%, p=0.002)$ and physical activity ( $90 \%$ vs $13 \%, p=0.002)$, and to have more comprehensive nutrition policies (average policy score out of 17: 11.8 vs. 9.0, $p=0.03$ ). Service provider policies and practices were more likely to promote healthy eating compared with healthy infant feeding, physical activity and screen time.

\section{Discussion}

Differences were found between FDC service providers trained or not trained in Munch \& Move regarding professional development and nutrition, physical activity and screen time policies but not in the resources provided. Other studies have generally found that professional development has improved both policies and resources ${ }^{11-13}$, however a recent US study, which focused on educator professional development, found no difference in nutrition, physical activity or screen time policies between intervention and control. ${ }^{14}$ The strong focus Munch \& Move places on training educators and implementing policies ${ }^{4}$ provides a possible explanation for the finding that service providers trained in the Munch \& Move program were more likely to provide healthy 
Table 1. Service provider practices of resource provision and educator professional development, and policy quality by service providers trained or not trained in Munch \& Move

\begin{tabular}{|c|c|c|c|c|}
\hline Service provider practices & $\begin{array}{c}\text { Number } \\
n(\%)\end{array}$ & $\begin{array}{c}\text { Trained in Munch \& } \\
\text { Move }(n=20) \\
n(\%)\end{array}$ & $\begin{array}{c}\text { Not trained in Munch \& } \\
\text { Move }(n=8) \\
n(\%)\end{array}$ & $p$-value \\
\hline \multicolumn{5}{|l|}{ Resources supplied to families ${ }^{a}$} \\
\hline Healthy eating & $26(93)$ & $18(90)$ & $8(100)$ & 1.000 \\
\hline Promoting physical activity & $19(68)$ & $15(75)$ & $4(50)$ & 0.371 \\
\hline Limiting screen time & $18(64)$ & $14(70)$ & $4(50)$ & 0.400 \\
\hline Breastfeeding & $16(57)$ & $13(65)$ & $3(38)$ & 0.231 \\
\hline Fussy eating & $13(46)$ & $12(60)$ & $1(13)$ & 0.058 \\
\hline Supervised floor-based play & $9(32)$ & $8(40)$ & $1(13)$ & 0.214 \\
\hline Introducing solids & $8(29)$ & $7(35)$ & $1(13)$ & 0.371 \\
\hline Fundamental movement skills & $6(21)$ & $6(30)$ & $0(0)$ & 0.141 \\
\hline \multicolumn{5}{|l|}{ Resources supplied to educators ${ }^{a}$} \\
\hline Healthy eating learning experiences & $25(89)$ & $19(95)$ & $6(75)$ & 0.188 \\
\hline Supervised floor-based play & $21(75)$ & $17(85)$ & $4(50)$ & 0.142 \\
\hline Fundamental movement skills & $21(75)$ & $17(85)$ & $4(50)$ & 0.142 \\
\hline List of physical activity equipment & $20(71)$ & $14(70)$ & $6(75)$ & 1.000 \\
\hline 'Breastfeeding welcome here' sign & $9(32)$ & $8(40)$ & $1(13)$ & 0.214 \\
\hline \multicolumn{5}{|l|}{$\begin{array}{l}\text { Professional development offered to } \\
\text { educators }\end{array}$} \\
\hline Healthy eating & $20(71)$ & $18(90)$ & $2(25)$ & 0.0002 \\
\hline Physical activity & $19(68)$ & $18(90)$ & $1(13)$ & 0.0002 \\
\hline Service provider policies ${ }^{b}$ & Total & $\begin{array}{c}\text { Trained in Munch \& } \\
\text { Move } \\
(n=20)\end{array}$ & $\begin{array}{l}\text { Not trained in Munch \& } \\
\text { Move } \\
(n=7)\end{array}$ & $p$-value \\
\hline \multicolumn{5}{|l|}{ Nutrition policy ${ }^{\mathrm{a}}$} \\
\hline$n(\%)$ & $27(100)$ & $20(100)$ & $7(100)$ & NA \\
\hline $\begin{array}{l}\text { Average policy score } \\
\text { (out of a total of } 17 \text { points) }^{c}\end{array}$ & 11.1 & 11.8 & 9.0 & 0.03 \\
\hline \multicolumn{5}{|l|}{ Infant feeding policy } \\
\hline$n(\%)$ & $24(89)$ & $19(95)$ & $5(71)$ & 0.16 \\
\hline $\begin{array}{l}\text { Average policy score } \\
\text { (out of a total of } 6 \text { points) }^{\circ}\end{array}$ & 3.1 & 3.2 & 2.7 & 0.52 \\
\hline \multicolumn{5}{|l|}{ Physical activity policy } \\
\hline$n(\%)$ & $11(41)$ & $7(35)$ & $4(57)$ & 0.39 \\
\hline $\begin{array}{l}\text { Average policy score } \\
\text { (out of a total of } 4 \text { points) }^{d}\end{array}$ & 2.3 & 2.5 & 1.9 & 0.56 \\
\hline \multicolumn{5}{|l|}{ Screen time policy } \\
\hline$n(\%)$ & $14(52)$ & $9(45)$ & $5(71)$ & 0.39 \\
\hline $\begin{array}{l}\text { Average policy score } \\
\text { (out of a total of } 6 \text { points) }^{d}\end{array}$ & 2.3 & 2.9 & 1.2 & 0.06 \\
\hline
\end{tabular}

NA = not applicable

a Fisher's exact tests

b 27 service providers provided policies to review. Average policy scores were calculated from service providers with a policy

Independent t-tests

d Mann-Whitney U test 
eating and physical activity professional development and have comprehensive nutrition policies.

Our study found most FDC service providers promoted nutrition and healthy eating messages through policies and resources provided to families and educators. However less information was provided about infant feeding, physical activity and screen time. Similar to our findings, studies in the US have demonstrated that family child care homes (equivalent to FDC) were more likely to provide families with information relating to nutrition than physical activity, and also hold more comprehensive nutrition policies than physical activity policies. ${ }^{15,16}$ It is unsurprising that fewer service providers in our study had comprehensive policies relating to infant feeding, physical activity and screen time as these are not mandated under national regulations. ${ }^{3}$ Of the limited studies conducted in Australian FDC services, Lum et al. ${ }^{17}$ found that more than two-thirds of FDC service providers in the NSW Hunter New England region of NSW had comprehensive nutrition policies but less than one-third had comprehensive physical activity and screen time policies and none had comprehensive infant feeding policies. Bravo et al. ${ }^{18}$ found that nutrition policies lacked detail and were not comprehensive. McGuire et al. ${ }^{19}$ qualitatively analysed infant feeding policies in Australian centre-based and FDC services, and found most policies focused on minimising risk within child care environments.

Limitations of our study include potential bias from self-reported data, and the survey and policy audit instruments not being validated. However, written policies were obtained to cross-check reporting and the policies were reviewed by two different researchers. The sample may not be representative of the FDC sector because of the low sample size and the high proportion of service providers who had previously participated in Munch \& Move training $(71 \%$ of participating service providers had completed the Munch \& Move training compared with $53 \%$ of all service providers who were invited to participate). The sample may not be adequately powered because of its small size. It is likely that recruitment was affected by state legislative changes that led to the closure of a high proportion of service providers ${ }^{20}$ and fee structure changes that increased administrative pressure. $^{20}$

\section{Conclusion}

Our findings suggest that Munch \& Move training had a positive impact on FDC service providers' policies and educators' professional development but service providers need additional support to adopt policies and to provide resources to educators and families, specifically targeting infant feeding, physical activity and screen time. Further research should investigate whether policies, resources and professional development provided by service providers to educators and families are associated with improvements in educator practices and whether they have a positive impact on children's physical activity and eating behaviours. Future studies are also needed to validate the policy review tool that could be used to assess other Australian ECEC services' policies.

\section{Acknowledgements}

This work was supported by the Prevention Research Support Program, funded by the NSW Ministry of Health.

\section{Peer review and provenance}

Not commissioned, externally peer reviewed.

\section{Competing interests}

None declared.

\section{Author contributions}

EK was responsible for acquisition of the data, policy review and drafting the article, and $\mathrm{MH}$ and $\mathrm{SR}$ contributed to the policy review. All authors contributed to the conception and design of the research, interpretation of data and critically revised the manuscript.

\section{References}

1. Australian Children's Education and Care Quality Authority. Guide to the National Quality Framework. Canberra: ACECQA; 2018 [cited 2021 Sep 10]. Available from: www.acecqa.gov.au/sites/default/files/2018-11/ Guide-to-the-NQF_0.pdf

2. Department of Education and Training. Child care in Australia. Canberra: Commonwealth of Australia; 2018 [cited 2019 Apr 26]. Available from: www.dese.gov.au/ key-official-documents-about-early-childhood/earlychildhood-and-child-care-reports/child-care-australiareport-december-quarter-2018

3. NSW Government. Education and Care Services National Regulations (2011 SI 653). Sydney: NSW Government; 2018 [cited 2019 Feb 6]. Available from: www.legislation. nsw.gov.au/\#/view/regulation/2011/653/chap4/part4.2/ $\operatorname{div} 1$

4. Lockeridge A, Innes-Hughes C, O'Hara BJ, Brian M, Rissel C. Munch \& Move: evidence and evaluation summary. Sydney: NSW Ministry of Health; 2015 [cited 2019 May 22]. Available from: healthykids.nsw.gov.au/ wp-content/uploads/2020/05/FINALMunchMoveSummary. pdf

5. NSW Government. Munch \& Move support. Sydney: NSW Government; 2020 [cited 2020 Aug 27]. Available from: healthykids.nsw.gov.au/munch-move-support/ 
6. Hardy LL, King L, Kelly B, Farrell L, Howlett S. Munch and Move: evaluation of a preschool healthy eating and movement skill program. Int J Behav Nutr Phys Act. 2010;7(1):80.

7. Australian Children's Education and Care Quality Authority. National registers. Canberra: ACECQA; 2019 [cited 2019 Sep 23]. Available from: www.acecqa.gov.au/ resources/national-registers

8. Australian Children's Education and Care Quality Authority. Quality area 2 - children's health and safety. Canberra: ACECQA; 2021 [cited 2021 Sep 15]. Available from: www.acecqa.gov.au/nqf/national-quality-standard/ quality-area-2-childrens-health-and-safety

9. Australian Bureau of Statistics. Socio-economic indexes for areas, Australia. Canberra: ABS; 2018 [cited 2019 Aug 12]. Available from: www.abs.gov.au/ausstats/ abs@.nsf/Lookup/by Subject/2033.0.55.001 2016 Main Features SOCIO-ECONOMIC INDEXES FOR AREAS (SEIFA) 2016 1

10. Australian Bureau of Statistics. The Australian statistical geography standard (ASGS) remoteness structure. Canberra: ABS; 2018 [cited 2019 Aug 12]. Available from: www.abs.gov.au/websitedbs/d3310114.nsf/home/ remoteness+structure

11. Woodward-Lopez G, Kao J, Kuo ES, James P, Lenhart K, Becker $\mathrm{C}$, et al. Changes in nutrition policies and dietary intake in child care homes participating in Healthy Eating and Active Living initiative. Am J Prev Med. 2018;54(5):S170-7.

12. Kao J, Woodward-Lopez G, Kuo ES, James P, Becker CM, Lenhart K, et al. Improvements in physical activity opportunities: results from a communitybased family child care intervention. Am J Prev Med. 2018;54(5):S178-85.
13. Trost SG, Messner L, Fitzgerald K, Roths B. A nutrition and physical activity intervention for family child care homes. Am J Prev Med. 2011;41(4):392-8.

14. Ward DS, Vaughn AE, Burney RV., Hales D, BenjaminNeelon SE, Tovar A, Ostbye T. Keys to healthy family child care homes: results from a cluster randomized trial. Prev Med (Baltim). 2020;132:105974.

15. Trost SG, Messner L, Fitzgerald K, Roths B. Nutrition and physical activity policies and practices in family child care homes. Am J Prev Med. 2009;37(6):537-40.

16. Gunter KB, Rice KR, Trost S. Nutrition and physical activity policies and practices in family child care homes in Oregon: baseline findings from the health home child care project. Ext J. 2012;50(3):3FEA3.

17. Lum M, Grady A, Falkiner M, Jones J, Finch M, Green S, et al. Assessing the implementation of healthy eating and physical activity policies and practices in the family day care setting: a cross sectional study. Heal Promot $\mathrm{J}$ Aust. 2020;1-10.

18. Bravo A, Cass Y, Tranter D. Good food in family day care: improving nutrition and food safety in family day care. Nutr Diet. 2008;65(1):47-55.

19. McGuire J, Gallegos D, Irvine S. Infant feeding nutrition policies in Australian early childhood education and care services: a content and qualitative analysis. Int J Child Care Educ Policy. 2018;12(1):14.

20. Family Day Care Australia. Family Day Care Australia submission to the Senate Select Committee on Red Tape inquiry into the effect of red tape on child care. NSW: Family Day Care Australia; 2018 [cited 2019 May 23] Available from: www.familydaycare.com.au/representingyou/submissions

\section{Copyright: (c) (i) () (2)}

(C) 2021 Kerr et al. This article is licensed under the Creative Commons Attribution-NonCommercial-ShareAlike 4.0 International Licence, which allows others to redistribute, adapt and share this work non-commercially provided they attribute the work and any adapted version of it is distributed under the same Creative Commons licence terms. See: www.creativecommons.org/licenses/by-nc-sa/4.0/ 